Article

\title{
Evaluation of Load Matching Indicators in Residential PV Systems-the Case of Cyprus
}

\author{
Vladimir Z. Gjorgievski ${ }^{1, *(1)}$, Nikolas G. Chatzigeorgiou ${ }^{2}$, Venizelos Venizelou ${ }^{2}$, \\ Georgios C. Christoforidis ${ }^{3}{ }^{-}$, George E. Georghiou ${ }^{2}$ and Grigoris K. Papagiannis ${ }^{4}$ \\ 1 Faculty of Electrical Engineering and Information Technologies, University Ss Cyril and Methodius, \\ 1000 Skopje, North Macedonia \\ 2 FOSS Research Centre for Sustainable Energy, PV Technology Laboratory, Department of Electrical and \\ Computer Engineering, University of Cyprus, 1678 Nicosia, Cyprus; nchatz05@ucy.ac.cy (N.G.C.); \\ venizelou.venizelos@ucy.ac.cy (V.V.); geg@ucy.ac.cy (G.E.G.) \\ 3 Department of Electrical and Computer Engineering, University of Western Macedonia, 50100 Kozani, \\ Greece; gchristo@teiwm.gr \\ 4 School of Electrical and Computer Engineering, Aristotle University of Thessaloniki, 54124 Thessaloniki, \\ Greece; grigoris@eng.auth.gr \\ * Correspondence: vladimir.gjorgievski@feit.ukim.edu.mk
}

Received: 3 March 2020; Accepted: 9 April 2020; Published: 15 April 2020

check for updates

\begin{abstract}
Three load matching indicators (self-consumption rate, self-sufficiency rate, loss of load probability) and the $\mathrm{CO}_{2}$ emissions were evaluated for 55 Cypriot households with $3 \mathrm{kWp}$ rooftop photovoltaic (PV) generators. The calculations were performed using 30-minute generation and consumption data from a large scale smart meter project in Cyprus. To investigate the effects of recent advances in local legislation, an analysis for higher PV capacities ( $5 \mathrm{kWp}$ and $10 \mathrm{kWp}$ ) was also performed. The PV generation profiles for $5 \mathrm{kWp}$ and $10 \mathrm{kWp}$ PVs were obtained by scaling the $3 \mathrm{kWp}$ PV generation profiles. The results showed that the self-consumption of the analyzed households varied seasonally, as it was related to their heating and cooling demand. More interestingly, the ratio between the households' annual electricity generation and demand, formally defined here as generation-to-demand ratio (GTDR), was found to be related to the value ranges of the studied load matching indicators. Hence, on average, households with $3 \mathrm{kWp}$ PV generators annually self-consumed $48.17 \%$ and exported $2,415.10 \mathrm{kWh}$ of their PV generation. On the other hand, households with larger PV generators were characterized by a higher GTDR, but lower load matching capabilities. For the cases of $5 \mathrm{kWp}$ and $10 \mathrm{kWp}$ PV generators, the average self-consumption fell to $34.05 \%$ and $19.31 \%$, while the exported PV generation was equal to 5,122.47 $\mathrm{kWh}$, and $12,534.90 \mathrm{kWh}$, respectively. Along with lower load matching capabilities, households that generated more than they consumed were also found to have a lower potential for $\mathrm{CO}_{2}$ emissions reduction per installed $\mathrm{kWp}$ within the boundaries of the building. In this context, the GTDR could be used by stakeholders to characterize buildings, infer possible value ranges of more complex indicators and make evidence based decisions on policy and legislation.
\end{abstract}

Keywords: photovoltaics; self-consumption; self-sufficiency; load matching indicators

\section{Introduction}

The need to reduce the energy and carbon intensity of buildings has transcended geographical boundaries. Global building-related $\mathrm{CO}_{2}$ emissions have been rising for two years in a row to a record high $9.6 \mathrm{GtCO}_{2}$, which is equivalent to $28 \%$ of the global emissions in 2018 [1]. This trend has been the result of the continuously growing energy demand, the decrease in energy intensity 
improvements in the building sector and the additional cooling load from the extreme temperature conditions [2]. Clearly, rapid and coordinated action is required to keep the building sector on track with sustainable development goals. In order to meet the 2-degree and 1.5-degree targets, in particular, the global emissions from the building sector should drop by $32 \mathrm{GtCO}_{2}$, and $50 \mathrm{GtCO}_{2}$, respectively [3]. This will likely be achieved through a combination of actions, such as the electrification of buildings [4], the integration of renewable energy sources (RES) [5] and deep retrofit measures [6]. Amidst this complexity, policy makers need to be guided by simple, but robust, indicators, in order to make evidence-based decisions.

Very commonly, the energy performance of buildings is benchmarked by the intensity of primary energy use, the building material characteristics, and the minimum requirements of the renewable energy share or by the $\mathrm{CO}_{2}$ emissions. These indicators are often found in the context of nearly zero energy buildings (NZEBs) which, in the EU, are regulated by the Energy Performance in Buildings Directive (EPBD) [7]. In essence, the framework set by the EPBD defines NZEBs as buildings with a very high energy performance that cover their low energy demand by on-site or nearby renewable energy generation. This definition is translated into legislation among the EU Member States in different ways, based on the national conditions [8].

One commonality among EU Member States is that the energy balance calculation for each building (the difference between the primary energy demand and the generated energy), is most often performed over a period of one year [9]. This approach does not take into account the energy exchange between the building and the networks of the different energy carriers. Hence, in the NZEB framework, the electricity grid is considered to be an ideal virtual storage unit [10]. As more distributed and variable generation becomes present, however, buildings are going to have a higher impact on the distribution grid. This is especially relevant in the case of rooftop solar photovoltaics (PVs), which have become key enablers of the building sector decarbonisation [11]. A Joint Research Centre (JRC) study has found that rooftop PVs can cover up to $24.4 \%$ of the EU electricity consumption based on 2016 values [5]. Nevertheless, high rooftop PV shares can lead to overvoltage and line overload in the distribution grid because they generate most of the energy during the daytime, when residential buildings are rarely occupied [12].

The PV-ESTIA project aims to address this issue by studying the barriers for larger PV deployment in buildings and exploring how energy storage in buildings can be used to tackle them [13]. To this context though, a deeper understanding of the energy performance of buildings without storage is required to provide a baseline. Load matching and grid interaction indicators are particularly useful for this as they describe the temporal mismatch between the generation and consumption in buildings. The authors of [14] have provided a summary of such indicators among which are the self-consumption rate (SCR), the self-sufficiency rate (SSR) and the loss of load probability (LOLP).

Load matching indicators are a useful tool for comparing different demand-side measures. They basically evaluate how well the generation and consumption profiles of the building match with respect to time. Hence, they have been found to be quite useful when studying the integration of rooftop PVs [15], batteries [16], thermal storage [17] and heat pumps [18]. The SCR is among the most commonly used load matching indicators [19]. It is used to infer the amount of PV generation which is consumed locally. As self-consumption is related to the daytime energy use, research has shown that factors, such as age, gender and the environmental motives of consumers have significant influence over it [20]. So far, there have been a variety of studies that evaluate self-consumption. Some of them focus on the economic performance [21] and the optimal orientation of rooftop PVs [22], while others investigate the long-term effects of self-consumption of a system level [23].

Due to the fact that analyses, related to the SCR have been extensively performed, this indicator has been most widely used to guide policy making. The EU, for instance, has provided Member States with best practice examples for self-consumption, with the aim of improving the energy flexibility of buildings [24]. However, the introduction of SCR in legislation is not easily done, as proven by the UK case where an assumed SCR value is used to calculate the electricity tariffs. To date, UK 
households with PVs are assumed to have a SCR of $45 \%$ by default. At the same time, their exports are not directly measured, but are considered to be equal to 50\% [25]. Despite this fact, [26] has found that a typical household with an annual electricity demand of $4000 \mathrm{kWh}$ and a $2.9 \mathrm{kWp}$ PV generator has a SCR of $37.3 \%$, and will more likely have exports in the range of $55-63 \%$. Such differences between the actual self-consumption and that assumed by legislation can lead to financial losses or false signals. Therefore, it is important that proper analyses on a representative case should be performed before making policy-related decisions. An example of such analysis is that of [27], which uses data from the Smart Grid Smart City project to find that households in Australia have a SCR of 31.3\%. Similarly, [28] explores the self-consumption on an international level, through the analysis of datasets from the UK, the USA, Australia, Germany, the Netherlands, and Belgium. Under some conditions, the evaluation of the monthly values of load matching indicators can also be useful. In the case of Greece, for instance, the monthly SCR values were calculated with the aim of exploring different net-metering policy options [29].

Besides SCR, other indicators, such as SSR, i.e., the cover factor for demand, and the loss of load probability (LOLP), have also been used in the literature [10]. However, their use has been rather limited when compared to that of SCR, which only contributes to their absence from legislation.

To that extent, this paper provides a statistical analysis of the energy performance of 55 households with PVs in Cyprus. By analyzing three load matching indicators (SCR, SSR and LOLP) it evaluates the benefits and drawbacks of installing larger rooftop PV capacities, as per the recent legislation changes in Cyprus. The analyzed measured data was obtained from a large-scale smart metering field project in Cyprus. As a main contribution, this paper identifies GTDR as a practical figure of merit which can be used to classify buildings with PVs for various policy measures related to load matching metrics. It was found that GTDR provides a reliable estimate to other indicators such as SSR, SCR and LOLP. The paper also contributes to the existing body of knowledge by investigating the relationship between load matching indicators and the $\mathrm{CO}_{2}$ emissions reduction. In this context, the $\mathrm{CO}_{2}$ emissions reductions within the boundaries of each household, as well as the $\mathrm{CO}_{2}$ emissions reduction due to the PV generation that is exported to the grid were estimated for different PV capacities.

\section{Materials and Methods}

This paper assesses the energy performance of households with rooftop PV generators. A dataset containing high quality measurements of the electricity consumption and PV generation of 55 Cypriot households was considered.

Three load matching indicators (SCR, SSR and LOLP) were used to evaluate how well the on-site PV generation coincides with the household's electricity consumption. Their values were calculated on a monthly as well as on an annual basis. The monthly values were used to explore how indicators varied among different months of the year. Furthermore, the 55 households were separated into three categories based on their generation-to-demand ratio (GTDR). The annual values of SCR, SSR and LOLP were then calculated for each generation-to-demand category. Moreover, the effects of different PV capacity limits on the values of the load matching indicators were studied. For this purpose, PV generation profiles for PV capacities of $5 \mathrm{kWp}$ and $10 \mathrm{kWp}$ were modelled by scaling the $3 \mathrm{kWp}$ generation data. These $5 \mathrm{kWp}$ and $10 \mathrm{kWp}$ limits represent past and current thresholds set in the Cypriot legislation for rooftop PV capacity. This analysis was performed using the energy matching chart proposed in [30]. Finally, the $\mathrm{CO}_{2}$ emissions and the emissions reduction due to the PV generation were analyzed within this context, for $3 \mathrm{kWp}, 5 \mathrm{kWp}$ and $10 \mathrm{kWp}$ PV generators. 


\subsection{Assessing the Load Matching Capabilities of Households}

The SCR represents the share of the PV generated energy which is consumed on-site. It is calculated as the ratio of the locally consumed PV generation and the overall PV generation,

$$
\mathrm{SCR}=\frac{\sum_{d=1}^{n_{d}} \sum_{t=1}^{24} \min \left(P_{\text {load }}(d, t), P_{p v}(d, t)\right) \Delta t}{\sum_{d=1}^{n_{d}} \sum_{t=1}^{24} P_{p v}(d, t) \Delta t},
$$

where $P_{\text {load }}(d, t)$ and $P_{p v}(d, t)$ denote average power of the electricity demand and the PV generation of day $d$ at time-step $t$, respectively, for the duration of each time step $\Delta t$. The number of days $n_{d}$ in (1) is determined by the time horizon of the calculation. It is equal to $n_{d}=365$ when the annual SCR is calculated or equal to the number of days of the corresponding month when the SCR is evaluated on a monthly basis.

The SSR assesses the share of the electricity demand which is covered by the rooftop PV generator. It is equal to the ratio of the locally consumed PV generation and the total electricity demand for a certain time period:

$$
\operatorname{SSR}=\frac{\sum_{d=1}^{n_{d}} \sum_{t=1}^{24} \min \left(P_{\text {load }}(d, t), P_{p v}(d, t)\right) \Delta t}{\sum_{d=1}^{n_{d}} \sum_{t=1}^{24} P_{\text {load }}(d, t) \Delta t} .
$$

Both SCR and SSR provide a qualitative evaluation of the PV generation share. For a quantitative analysis of the PV generation share, LOLP and GTDR have been calculated.

The percentage of time during which a household with a rooftop PV generator acts as a net consumer is defined by the LOLP. This indicator is calculated as follows,

$$
\text { LOLP }=\frac{t_{P_{\text {load }}>P_{p v}}}{T}
$$

where $T$ is equal to the total number of time-steps in the analyzed time horizon.

The values of these load matching indicators vary between 0 and $100 \%$, depending on the load profile and the capacity of the rooftop PV generator. A household with a high electricity demand and a small PV generator is likely to locally consume a larger share of the PV generation. In other words, it is likely to have better load matching capabilities than a household where the inverse is true. Therefore, it is convenient to categorize different households with respect to their annually consumed and generated energy. The GTDR is a useful parameter for such analyses. Although this ratio has been used sporadically in the literature $[15,19,30]$, here it has been formally defined as:

$$
\mathrm{GTDR}=\frac{\sum_{d=1}^{n_{d}} \sum_{t=1}^{24} P_{p v}(d, t) \Delta t}{\sum_{d=1}^{n_{d}} \sum_{t=1}^{24} P_{\text {load }}(d, t) \Delta t}=\frac{E_{p v}}{E_{\text {load }}}=\frac{\mathrm{SSR}}{\mathrm{SCR}}
$$

GTDR is calculated as the ratio of the generated and the consumed energy over a certain time horizon which is usually equal to one year. Considering (1) and (2), GTDR is also equal to the ratio of SSR and SCR. 


\subsection{Estimation of $\mathrm{CO}_{2}$ Emissions}

The amount of $\mathrm{CO}_{2}$ that is emitted in the atmosphere as a result of the electricity consumption of a household is proportional to the household's net electricity demand (NED):

$$
\mathrm{NED}=\sum_{d=1}^{n_{d}} \sum_{t=1}^{24} \max \left(P_{\text {load }}(d, t)-P_{p v}(d, t), 0\right) \Delta t
$$

The equivalent $\mathrm{CO}_{2}$ emissions for each period can therefore be estimated using the grid factor $\mathrm{GF}_{\mathrm{CO} 2}$ :

$$
\mathrm{CO}_{2}=\mathrm{GF}_{\mathrm{CO} 2} \mathrm{NED} \text {. }
$$

The grid factor $\mathrm{GF}_{\mathrm{CO} 2}$ expresses the emissions intensity in $\mathrm{kgCO}_{2} / \mathrm{kWh}$ of a unit of generated electricity for a specific power system. Using (5) and (6) one can easily calculate the $\mathrm{CO}_{2}$ emissions for a household with a rooftop PV generator, $\mathrm{CO}_{2(\mathrm{pv})}$. To calculate the equivalent emissions of a household without a PV generator $\left(\mathrm{CO}_{2 \text { (no pv) }}\right)$, the term $P_{p v}(d, t)$ is omitted from (5).

The reduction of a household's $\mathrm{CO}_{2}$ emissions, resulting from the installation a rooftop PV generator can be estimated using the following equation:

$$
\Delta \mathrm{CO}_{2}(\%)=\frac{\mathrm{CO}_{2(\text { no }} \text { pv) }-\mathrm{CO}_{2(p v)}}{\left.\mathrm{CO}_{2(\text { no }} p v\right)} \cdot 100 .
$$

Not all of the PV generation is consumed on-site. The exported PV generation $E_{\text {grid,ex }}$ is equal to:

$$
E_{\text {grid }, e x}=\sum_{d=1}^{n_{d}} \sum_{t=1}^{24}\left|\min \left(P_{\text {load }}(d, t)-P_{p v}(d, t), 0\right)\right| \Delta t,
$$

The exported electricity will be consumed by the neighboring buildings, thereby, yielding additional emissions reductions $\mathrm{CO}_{2(\mathrm{ex})}$ equal to:

$$
\mathrm{CO}_{2(\mathrm{ex})}=\mathrm{GF}_{\mathrm{CO} 2} E_{\text {grid,ex }} \text {. }
$$

\subsection{Input Data}

As part of the SmartPV project [31], detached residential households in Cyprus were selected for the integration of the first pilot smart meters in the island in 2015 [32]. The selected households (55 in total) are widespread all over the non-occupied part of Cyprus, distributed in 4 different provinces. All households were equipped with $3 \mathrm{kWp}$ rooftop PV generators under the net-metering scheme, which during the time of installation, was the maximum allowed residential PV capacity. In addition, net-metering is the only available (but still widely exploited) compensation mechanism in Cyprus for residential PV purposes. All PV systems are installed at an approximately $30^{\circ}$ inclination angle due South, which is the optimal fixed orientation for PV systems in Cyprus. The households were randomly selected, in order to take different types of consumers, as well as different PV system manufacturers into account. All households were connected to the grid via a single-phase connection.

Hence, two single-phase smart meters were installed in the selected households for the data collection purposes. Specifically, the first smart meter was placed at the output of the PV inverter (PV system's AC-side), while the other was placed at the point of connection of the household with the distribution grid. As a result, both smart meters shared a common AC bus, as illustrated by the simple block diagram of the selected pilots in Figure 1. The main objective of the above was the collection of data concerning the PV system's operation, as well as the household's interaction with the distribution grid. All collected values were transferred to a local database in real-time. A set of high-quality annual power data for the period from January to December 2018 were available for the purposes of this research work. Specifically, the PV generation, the grid import and the grid export were collected in 
30-minute time intervals. This dataset was then post-processed to obtain the load consumption values, using the following equation,

$$
P_{\text {load }}(d, t)=P_{p v}(d, t)+P_{\text {grid,im }}(d, t)-P_{\text {grid,ex }}(d, t),
$$

where $P_{\text {grid,ex }}(d, t)$ and $P_{\text {grid,im }}(d, t)$ denote the power that is exported to and imported from the grid, respectively. All 55 households of this study have full PV generation and demand profiles for the whole year.

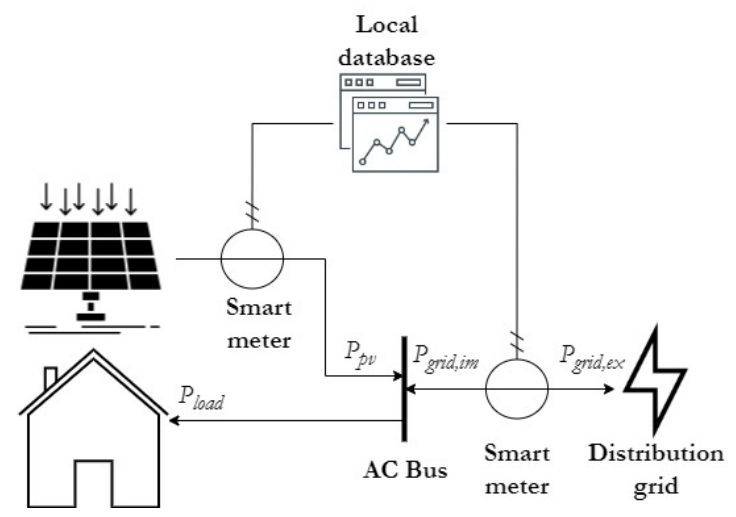

Figure 1. Simple block diagram of the selected pilots in Cyprus.

Table 1 illustrates the annual PV generation and electricity consumption values of these households. The calculated average value of electricity consumption of the sample $(7179.40 \mathrm{kWh})$ is comparable, despite being slightly higher, to the average electricity consumption per household as stated by the Statistical Service in Cyprus (6288 kWh) [33]. Figures 2 and 3 demonstrate the monthly electricity demand and the monthly PV generation for all analyzed households, respectively. It can be observed that the maximum PV generation occurs during the period of highest electricity demand (i.e., summer), which is a result of increased space cooling needs. Moreover, it should be noted that a relatively high difference in the consumption levels of the analyzed households can be observed, due to the diversity of the sample.

Table 1. Annual electricity generation and consumption of the analyzed households $(n=55)$.

\begin{tabular}{ccc}
\hline Value & Consumption (kWh) & Generation $(\mathbf{k W h})$ \\
\hline Average & $7,179.40$ & $4,660.86$ \\
Minimum & $4,729.00$ & $3,839.72$ \\
Maximum & $15,426.12$ & $5,272.30$ \\
Std. deviation & $2,168.53$ & 332.25 \\
\hline
\end{tabular}

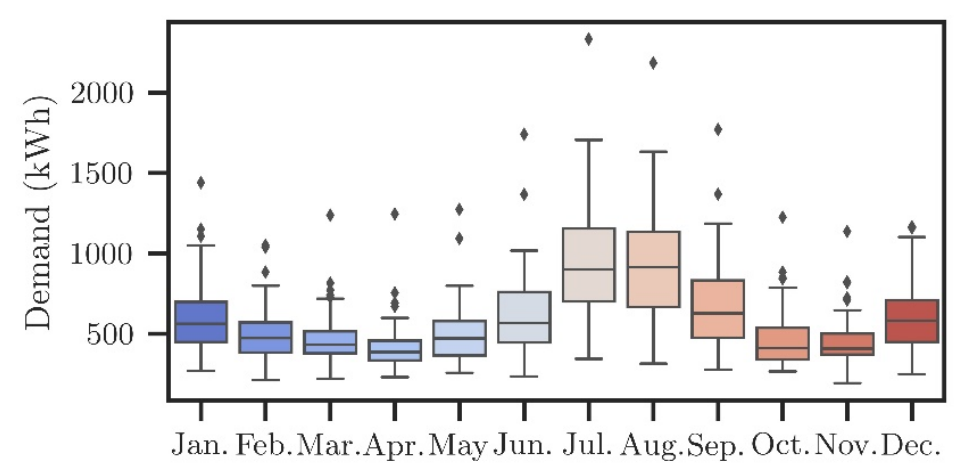

Figure 2. Household electricity demand $(n=55)$. 


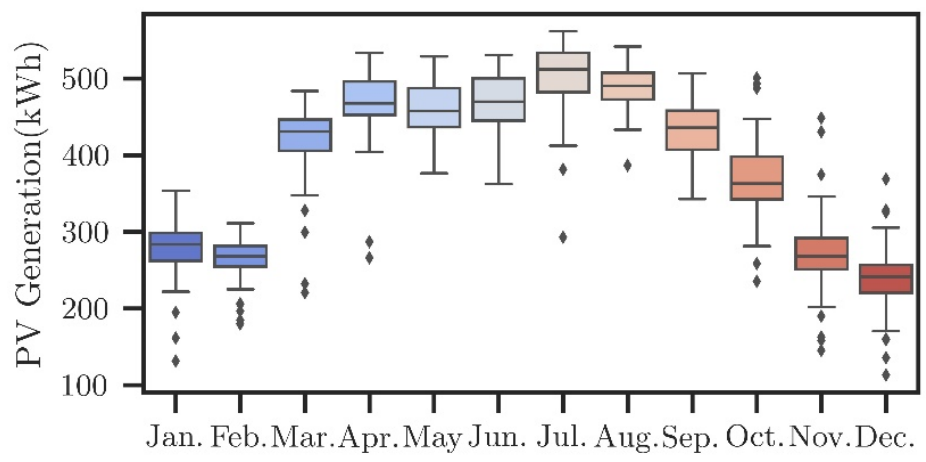

Figure 3. PV generation per household; the PV capacity of all analyzed households is $3 \mathrm{kWp}(\mathrm{n}=55)$.

This diversity of the consumption profiles was a result of the differences in households' occupancy levels and the differences of each building's equipment. Last, it is worth noting that PV generators were not installed with an optimal capacity in relation to the consumption levels of each household as their capacity was restricted by the limits found in the legislation at that time.

\section{Results}

\subsection{Load Matching Indicators}

Although, differences appear with regard to their consumption profiles, the analyzed households had some underlying commonalities when it comes to their energy performance. This became evident when the monthly and annual values of the load matching indicators were studied.

\subsubsection{What Drives Self-Consumption in Households?}

The monthly SCR of the analyzed households is shown in Figure 4. The boxplot depiction of the results essentially shows that, in Cypriot conditions, large self-consumption should be expected either, in the summer time, when the cooling demand is high, or during the winter, when the PV generation is significantly lower compared to the summer season. In spring and autumn, the household's electricity demand is usually lower due to the lack of cooling or heating needs. This, in turn, leads to a lower PV self-consumption. Individual cases where almost all of the PV generation was consumed on-site (SCR $\geq 80 \%$ ) were found in all months. This, nevertheless was not the norm. Highest individual self-consumption was noted in July (SCR $=94.96 \%$ ), which together with January, June, August and December were the months with the highest average SCR values. On the contrary, March, April and October were the months with the lowest SCR, during which a minimum SCR occurred in March (SCR $=19.20 \%$ ). The average monthly SCRs ranged from $37.43 \%$ to $59.37 \%$.

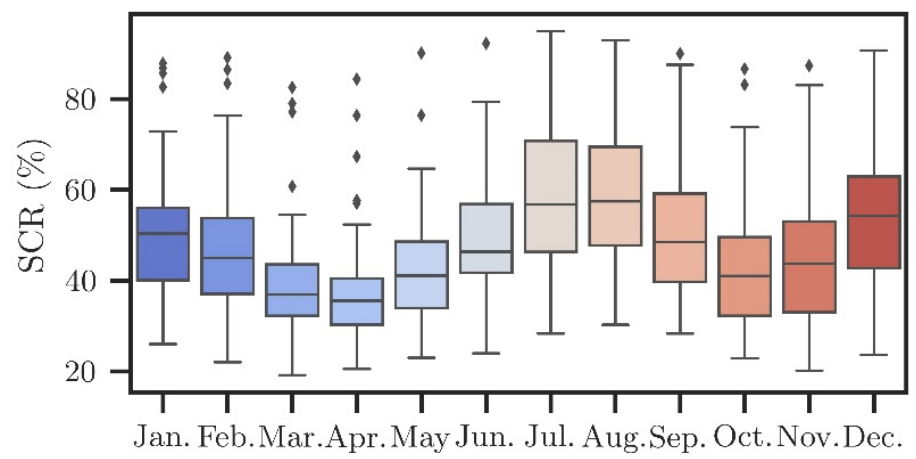

Figure 4. Monthly SCR values of the analyzed households $(n=55)$.

The share of electricity demand which is offset by the PV generation is represented by the SSR and is shown in Figure 5. The self-sufficiency of the households was lowest in summer and winter, when 
the gross electricity demand is much higher than the PV generation. On average, SSR ranges from $21.94 \%$ in December to $41.62 \%$ in April. At the same time, the case of highest single SSR was noted in June, while the lowest SSR of only $8.33 \%$ was found in December. Interestingly, low SSR values were noted for months of high self-consumption.

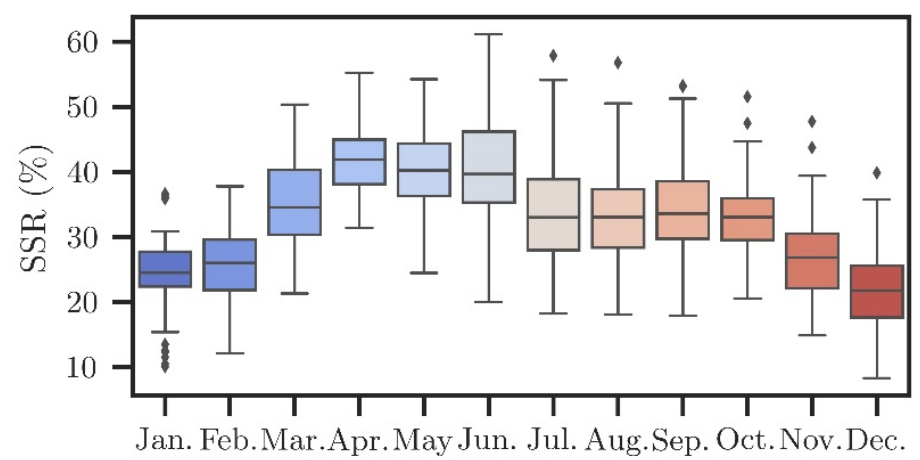

Figure 5. Monthly SSR values of the analyzed households $(n=55)$.

As depicted in Figure 5, a steep increase of the SSR is observed for the month of March. This rise is a result of the increased PV generation, exhibited during that month, as well as the net-metering annual "energy credit" expiration. According to the Cypriot net-metering legislation, for a bi-monthly billing schedule, the last electricity bill of the offsetting year is considered to be the one recorded in February or March. For the monthly billing, where the recording is made monthly, the last account of the clearing year is the prosumer account for which the measurement was recorded in March. Any excess credits are lost and not compensated at the end of a prosumer's annual period [34]. For an easy comparison, as part of the SmartPV project, the selected sample was moved to a bi-monthly billing schedule where any excess of "energy credits" were offset at the end of March. The results of a survey questionnaire, conducted as part of the project [35], indicated that prosumers tend to deliberately increase their self-consumption levels during the offsetting month, in order to avoid any adverse loss of "energy credits".

While, SCR and SSR evaluate the share of PV generation rather qualitatively, LOLP addresses the same issue in a more quantitative and holistic manner. In doing so, LOLP reveals how often these households consume electricity from the grid. The results shown in Figure 6 represent the monthly values of LOLP. Their general trend throughout the year is roughly described by an asymmetrical "W" shape, with highest values in the winter months, and smaller periodical increase in the summer. This trend is symmetrically inverse to the trend described by SSR.

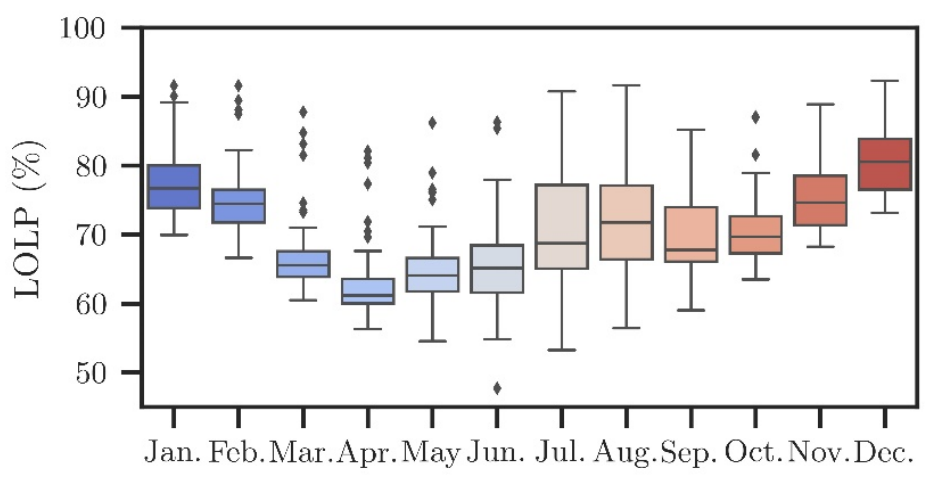

Figure 6. Monthly LOLP values of the analyzed households $(n=55)$.

On average, the analyzed households most frequently consumed electricity from the distribution grid in December. This is a result of the low PV generation during this month, thus, leading to the highest average LOLP value of $80.56 \%$. On a case by case basis, the highest LOLP was also found in 
December when a household was independent from the grid for $7.66 \%$ of the month (LOLP $=92.34 \%$ ). On the contrary, lowest average grid reliance, noted by low average LOLP, was found in April. This fact relates well with the high self-sufficiency noted in April (Figure 5) when the average SSR was equal to $41.62 \%$.

\subsubsection{Effects of Generation-to-Demand Ratio on Load Matching Indicators}

The average, minimum and maximum values of the load matching indicators, which are calculated for a time horizon of one year, are provided in Table 2. Careful considerations must be made before generalizing the conclusions to all Cypriot households, given they are obtained from a limited dataset. Nevertheless, these results provide a solid initial insight of the indicator values which can be crucial for making informed policy decisions. In that regard, to the best of the authors' knowledge and considering the limited data availability, these are the most elaborate evaluation of SCR, SSR and LOLP for the case of Cyprus.

Table 2. Annual values for the load matching indicators $(n=55)$.

\begin{tabular}{ccccc}
\hline Value & SCR (\%) & SSR (\%) & LOLP (\%) & GTDR \\
\hline Average & 48.17 & 31.77 & 71.02 & 0.70 \\
Minimum & 28.63 & 20.20 & 63.03 & 0.33 \\
Maximum & 88.24 & 42.21 & 86.08 & 0.99 \\
Std. deviation & 12.46 & 4.89 & 4.97 & 0.17 \\
\hline
\end{tabular}

Table 2 shows that the average annual SCR is equal to $48.17 \%$, while the reduction of the annual electricity demand due to the rooftop PV generated ranges from $20.20 \%$ to $42.21 \%$ with an average value of $31.77 \%$. To an extent, these results are comparable with those obtained in [26] and [27]. With regards to the SCR, [26] found that the SCR of a typical UK household with a $2.9 \mathrm{kWp}$ PV generator was equal to $37.3 \%$, while the average SCR of the dataset was equal to $45 \%$. Similarly, [27] showed that the average SCR for houses in Australia is about 31\%. The SCR for the analyzed Cypriot households $(48.17 \%)$ is, therefore, higher than that in the UK (37.3\%) and Australia (31.3\%). In the analyses of [26], the annual demand reduction was found to be $24 \%$. These differences occur as a result of the different solar potential and demand patterns among the UK, Australia and Cyprus. More precisely, the typical UK household has an annual demand of about $4000 \mathrm{kWh}$ and generates $2900 \mathrm{kWh}$, while the typical Australian house has an annual consumption of about $6460 \mathrm{kWh}$. From what has been provided in [27], no information could be inferred with regards to the PV generation. The analyzed sample for Cyprus, on the other hand, has an average electricity demand of $7179.40 \mathrm{kWh}$ and an average PV generation of $4660.86 \mathrm{kWh}$. Similar to the case of the UK, where the average fraction of daytime electricity use ranged from 0.25 to 0.28 , the average share of daytime electricity use for the analyzed Cypriot households was equal to 0.25 .

The relatively high load matching capabilities of the studied households, however, do not imply that they are not reliant on the distribution grid. Quite the contrary, the LOLP values, provided in Table 2, show that the households relied on the distribution grid, in order to consume electricity for at least $63.03 \%$ of the time.

Yet, not all households have equal load matching capabilities. For instance, households that generate much less than they consume, i.e., that have a low GTDR, are likely to export only a small fraction of the PV generation to the grid. On the opposite side, households with a high GTDR are expected to export more energy back to the distribution grid. This case is noted with low SCR and LOLP values and high SSR values. Figure 7 depicts boxplots of a low, medium and high GTDR. The households were considered to have a low GTDR if it ranged from 0.3 to 0.6 , a medium GTDR if it ranged from 0.6 to 0.8 and a high GTDR if their ratio was higher than 0.8 . These thresholds were arbitrarily chosen in order to evenly distribute the households in each category as much as possible. 
Separating households into categories in this manner enables decision makers to easily obtain an estimate of the load matching capabilities for different types of households.

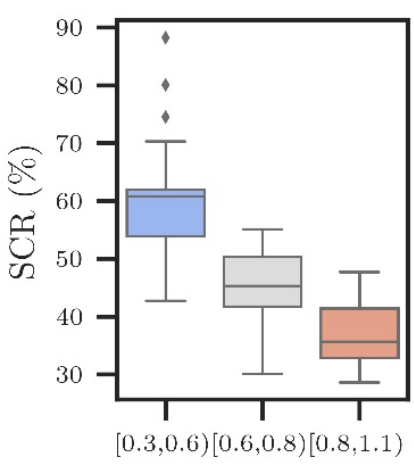

(a)

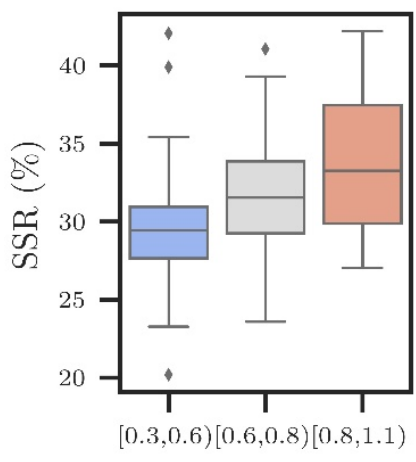

(b)

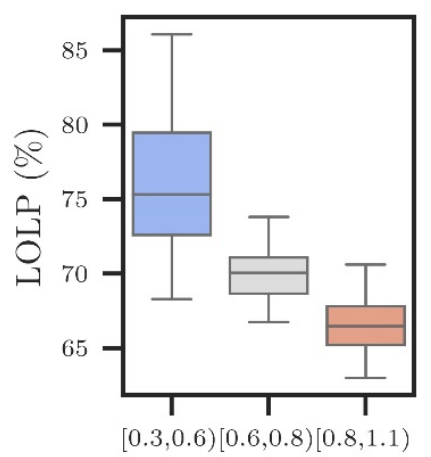

(c)

Figure 7. Load matching indicator values for different ranges of the generation-to-demand ratio GTDR; (a) SCR; (b) SSR; (c) LOLP ( $\mathrm{n}=55)$.

The prosumers with low GTDR generated $30-60 \%$ of their annual electricity demand. However, their actual electricity demand was reduced by $20.20 \%-42.06 \%$, or $29.95 \%$, on average. Due to the low PV output, they relied on the grid for $76.28 \%$ of the year, but consumed a relatively high share of their PV generation (SCR $=61.63 \%$ ). The households with medium GTDR are depicted with light-gray colored boxplots in Figure 7. Their SCR ranged from 30.08\% to 55.09\% with an average value of $45.13 \%$. The higher PV generation led to greater reductions of the annual demand (31.81\% on average) and a notably lower grid reliance (LOLP $=69.84 \%$ ) compared to the households with low GTDR. Finally, the households which generated at least $80 \%$ of their annual demand (GTDR $\geq 0.8$ ) were found to have the lowest self-consumption. Their SCR ranged from $28.63 \%$ to $47.73 \%$, with an average value of $37.27 \%$.

At the cost of exporting the majority of their PV generation to the distribution grid, these households were, nevertheless, found to be most self-sufficient. As anticipated, their average electricity demand reduction was highest (SSR $=33.90 \%$ ) and they consumed energy from the grid for the least amount of time compared to the other categories (LOLP $=66.68 \%$ ).

\subsection{Exploring the Impacts of Higher PV Capacities}

The analyses provided above were obtained from a set of households with $3 \mathrm{kWp}$ PV generators. Nevertheless, in 2016, the maximum allowed residential PV capacity in Cyprus was increased to $5 \mathrm{kWp}$ [36], followed by a further increase to $10 \mathrm{kWp}$ in 2018 [37]. In order to evaluate the effects of these PV capacities on the energy performance of the households, the $3 \mathrm{kWp}$ PV generation was scaled to equivalent $5 \mathrm{kWp}$ and $10 \mathrm{kWp}$ generation profiles (denoted as " $5 \mathrm{kWp}$ " and "10 $\mathrm{kWp}$ " in the tables and figures). At the same time, it was assumed that households have not changed their demand profiles. The analysis was performed within the graphical framework of the energy matching chart, as shown in Figure 8.

Each point in the chart represents a household through its annual SCR and SSR. Households found below the dotted grey line are net consumers, i.e., have a GTDR $<1$. The households that are represented with points above the dotted grey line are net producers (GTDR $>1$ ). Finally, in case a household generates as much as it consumes (GTDR $=1)$, then it has equal SCR and SSR values and is located on the grey line. The top right corner of the energy matching chart thus depicts a case of a perfect load matching. 


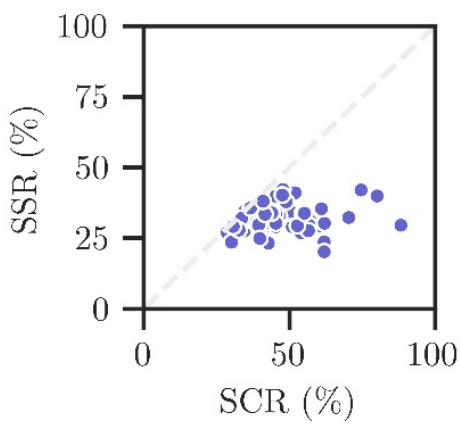

(a)

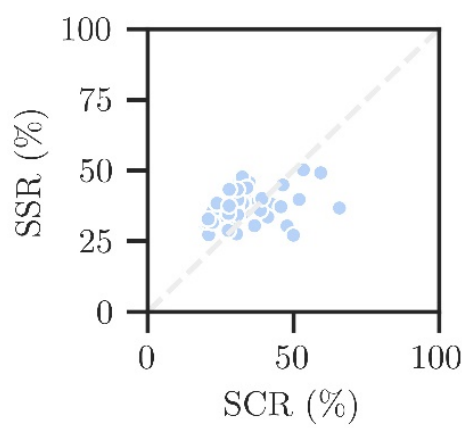

(b)

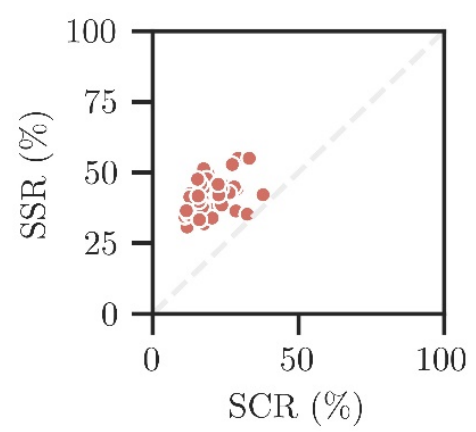

(c)

Figure 8. Effects of different PV capacities on households' energy performance; (a) $3 \mathrm{kWp}$; (b) $5 \mathrm{kWp}$; (c) $10 \mathrm{kWp}$ ( $\mathrm{n}=55)$; ( upscaled from $3 \mathrm{kWp}$ PV generation profiles).

Figure 8a depicts the energy matching chart for the case of households with $3 \mathrm{kWp}$ PV generators. The results demonstrate that, for the given dataset, a $3 \mathrm{kWp}$ generator was insufficient to cover the annual demand, thus making the households net consumers. The SCR, SSR and LOLP ranges were equal to $28.63-88.24 \%, 20.20-42.21 \%$, and $63.03-86.08 \%$, respectively, as shown in Figure 9 . About $90 \%$ of the analyzed households covered at least $25 \%$ of their annual electricity demand from RES when a $3 \mathrm{kWp}$ generator was installed. Furthermore, Figure $8 \mathrm{~b}$ illustrates the energy performance of the households with a $5 \mathrm{kWp}$ PV generator. It was found that the analyzed households self-consumed between $1388 \mathrm{kWh}$ and $5665 \mathrm{kWh}$. With an average SCR of 34.05\%, they reduced their annual electricity demand by $2645 \mathrm{kWh}$ and exported about $5122.47 \mathrm{kWh}$. The mean SSR in this case was equal to $37.05 \%$. Moreover, the SSR and SCR values for the $5 \mathrm{kWp}$ case were rather close. As a consequence, when the households were analyzed with $5 \mathrm{kWp} \mathrm{PV}$, most of them generated as much as they consumed. More specifically, the average GTDR was equal to 1.16 and the standard deviation was equal to 0.29 .

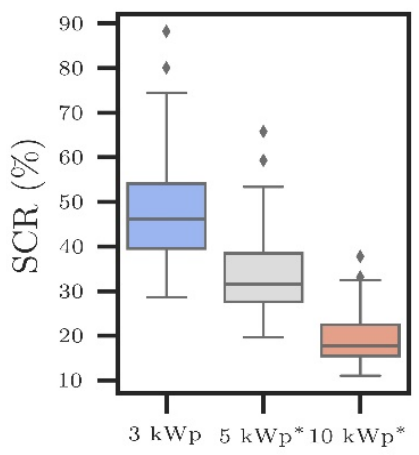

(a)

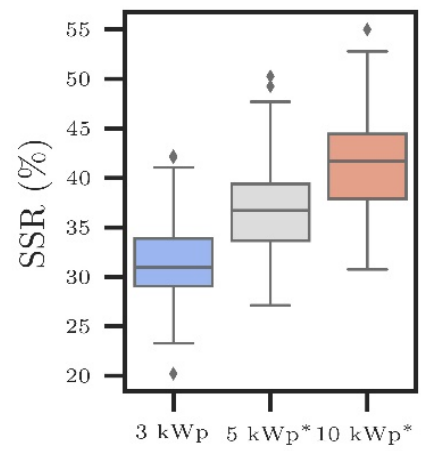

(b)

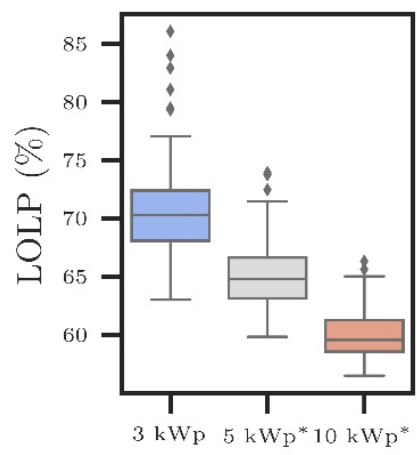

(c)

Figure 9. Load matching indicator values for different rooftop PV capacities; (a) SCR; (b) SSR; (c) LOLP ( $n=55)$. (* upscaled from $3 \mathrm{kWp}$ PV generation profiles).

Finally, the analysis of the case for $10 \mathrm{kWp}$ PV capacity is shown in Figure 8c. When the energy performance of the households was analyzed assuming a $10 \mathrm{kWp} \mathrm{PV} \mathrm{generator} \mathrm{was} \mathrm{installed} \mathrm{instead} \mathrm{of}$ the $3 \mathrm{kWp}$ PV generator, all of the households generated more than they annually consume (minimum GTDR $=1.09$ ). In some cases, the PV generation exceeded the annual demand by a factor of 3.33 (maximum GTDR = 3.33). The average GTDR of the analyzed households was equal to 2.32.

One should acknowledge that the $10 \mathrm{kWp}$ PV generator may not be most cost optimal solution for every household. Regardless, this analysis focuses on investigating the impact that a PV generator of this capacity would have on the analyzed sample population. Since all households generated more 
than they consumed, their electricity exports were, on average, equal to $12,534.90 \mathrm{kWh}$, i.e., about $80 \%$ of their PV generation. When compared to the $3 \mathrm{kWp}$ and $5 \mathrm{kWp}$ calculations, this resulted in additional exports of 10,119.80 $\mathrm{kWh}$ and $7412.41 \mathrm{kWh}$, respectively. On the other hand, the average self-consumed PV generation was equal to $3001.32 \mathrm{kWh}$ (average SCR $=19.31 \%$ ).

Despite the increased PV generation, the households with $10 \mathrm{kWp}$ PVs still relied on the distribution grid between $56.48 \%$ and $66.32 \%$ of the year. This is not a notable improvement when compared to the $3 \mathrm{kWp}$ and $5 \mathrm{kWp}$ cases (Figure 9c), especially if one considers that the self-sufficiency of the households was increased by only $10.00 \%$ and $4.72 \%$, compared to the $3 \mathrm{kWp}$, and $5 \mathrm{kWp}$ cases, respectively. This shows that excessive PV capacity yields low SCR in the absence of demand side measures or suitable energy storage systems.

\subsection{Relationship Between Load Matching and $\mathrm{CO}_{2}$ Emissions}

Figure 10 depicts the monthly variation of the $\mathrm{CO}_{2}$ emissions throughout the year. The results show that the emissions follow the same annual trend as the net energy consumption of the household. The grid factor in Cyprus for the analyzed year was equal to $\mathrm{GF}_{\mathrm{CO} 2}=73.52 \mathrm{gCO}_{2} / \mathrm{kWh}$ (provided on the pack page of electricity bill in Cyprus (see supplementary materials), calculated as in [38]). When the households were analyzed without a PV generator (Figure 10a), their average monthly emissions ranged from $310.92-679.19 \mathrm{kgCO}_{2}$, with the extremes occurring in April and July, respectively. Installing a $3 \mathrm{kWp}$ PV was found to reduce the monthly average of the $\mathrm{CO}_{2}$ emissions by $89.55-217.45 \mathrm{kgCO}_{2}$, with the smallest reduction occurring in February and the largest reduction occurring in July (from comparison of Figure 10a,b). As a result, the average households' emissions with $3 \mathrm{kWp}$ PVs ranged between $183.97-465 \mathrm{kgCO}_{2}$. The distribution of the emissions within each month is more elaborately shown in Figure 10.

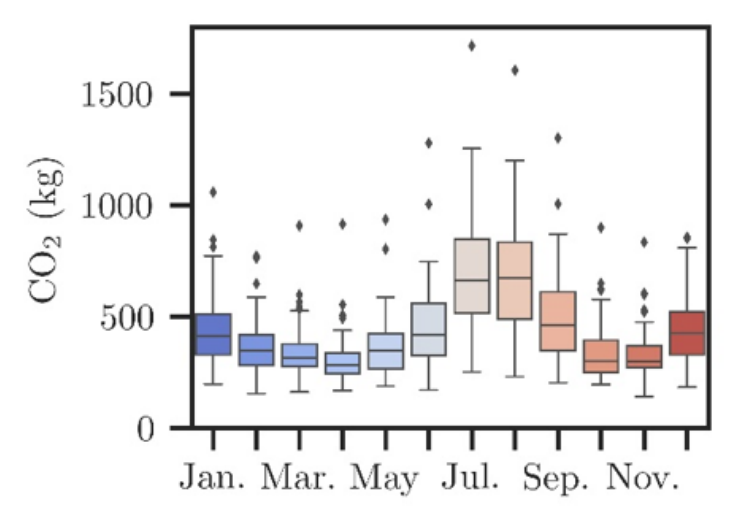

(a)

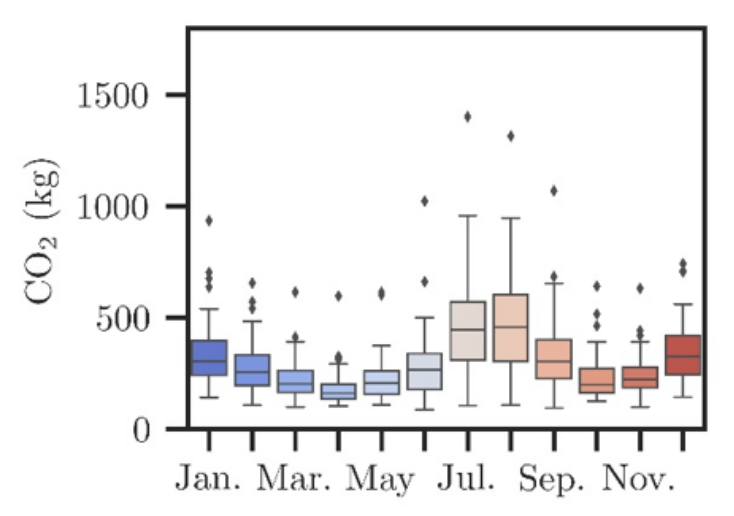

(b)

Figure 10. Household $\mathrm{CO}_{2}$ emissions from electricity consumption; (a) no PV generator installed; (b) $3 \mathrm{kWp}$ PV generator installed. $(\mathrm{n}=55)$.

On an annual basis, the 55 analyzed households emitted an average of $5278.37 \mathrm{kgCO}_{2}$ due to their electricity consumption, as shown in Table 3. This value is comparable to the average emissions of a 99 household dataset from Texas, US that has an average electricity demand of about 11,500 kWh (the average demand of the dataset analyzed in this paper was $7179.40 \mathrm{kWh}$ ) [39]. The results indicate that the electricity consumption in Cyprus is more carbon intensive than that of Texas. The high solar irradiation combined with the highly carbon intensive power sector makes the installation of rooftop PVs very convenient in Cyprus. PVs can offset a part of the households' demand by supplying it locally, instead of through the dominantly fossil fuel-based power system, and thus, reduce the island's overall emissions. 
Table 3. $\mathrm{CO}_{2}$ emission and average $\Delta \mathrm{CO}_{2}$ emissions for different $\mathrm{PV}$ capacities $(\mathrm{n}=55)$.

\begin{tabular}{ccccc}
\hline Value & $\mathbf{N o} \mathbf{P V}$ & $\mathbf{3} \mathbf{k W} \mathbf{p}$ & $\mathbf{5} \mathbf{k W} \mathbf{p}^{*}$ & $\mathbf{1 0} \mathbf{k W}$ * \\
\hline $\mathrm{CO}_{2, \text { average }}(\mathrm{kg})$ & $5,278.37$ & $3,627.26$ & $3,333.28$ & 3071.77 \\
$\mathrm{CO}_{2, \min }(\mathrm{kg})$ & $3,476.80$ & $2,240.16$ & $2,041.83$ & $1,901.12$ \\
$\mathrm{CO}_{2, \max }(\mathrm{kg})$ & $11,341.44$ & $8,267.92$ & $7,550.31$ & $6,707.52$ \\
$\Delta \mathrm{CO}_{2}(\%)$ & - & 31.77 & 36.85 & 41.80 \\
\hline
\end{tabular}

(* upscaled from $3 \mathrm{kWp}$ PV generation profiles)

Installing a $3 \mathrm{kWp}$ PV generator was found to reduce the annual emission by $882.33-3,351.49 \mathrm{kgCO}_{2}$, or $1651.11 \mathrm{~kg} \mathrm{CO}_{2}$, on average. This is equivalent to an average annual reduction of $31.77 \%$. For larger PV capacities, the $\mathrm{CO}_{2}$ emissions reduced even further, although the relation between the PV capacity and the $\mathrm{CO}_{2}$ reduction was not linear. For instance, a $5 \mathrm{kWp}$ PV generator reduced $\mathrm{CO}_{2}$ emissions in the range of $1020.95-4164.81 \mathrm{kgCO}_{2}$, or $1945.09 \mathrm{kgCO}_{2}$ on average. On the other hand, a $10 \mathrm{kWp}$ PV generator was found to reduce the $\mathrm{CO}_{2}$ emissions between $1150.67-4782.00 \mathrm{kgCO}_{2}\left(2206.59 \mathrm{kgCO}_{2}\right.$ on average).

This is explained by the relationship between the $\mathrm{CO}_{2}$ emissions and the self-sufficiency of the household. The analysis showed that the reductions of the $\mathrm{CO}_{2}$ emissions $\left(\Delta \mathrm{CO}_{2}\right)$ are equal to the value of the SSR for each household. This observation is clearly shown in Figure 11 where $\Delta \mathrm{CO}_{2}$ has been plotted against SSR. Since the $\mathrm{CO}_{2}$ emissions were estimated using the grid factor, these results are not unexpected, as both SSR and $\Delta \mathrm{CO}_{2}$ are proportional to the reduction of the gross electricity demand. The findings elaborated above shed light on the relevance of the SSR as a load matching indicator. As its value is a clear indication of the relative emissions reduction, its enhanced integration into legislation could contribute to the debate related to the energy performance of buildings.

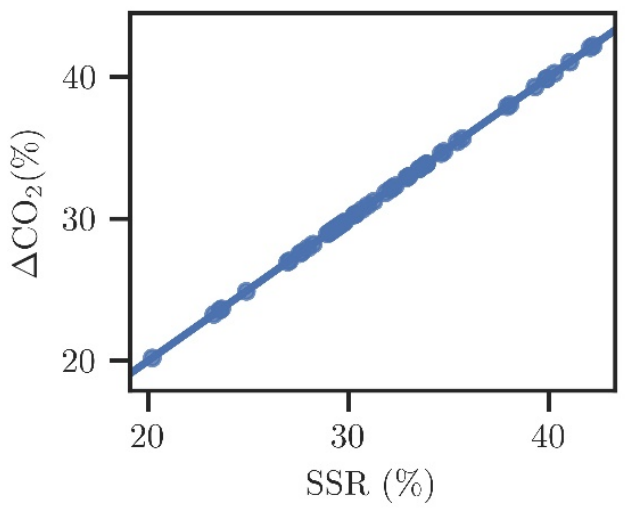

Figure 11. Correlation between annual self-sufficiency and reduction of $\mathrm{CO}_{2}$ emissions ( $3 \mathrm{kWp} \mathrm{PV).}$

The improvement of a household's SSR, however, is limited by its load matching capabilities. After a certain PV capacity threshold, the incremental improvement in the SSR is reduced, as the household simply cannot consume more energy locally and the energy from the additional PV capacity is exported to the grid [40]. As a result, the emissions for the $10 \mathrm{kWp} \mathrm{PV} \mathrm{generator} \mathrm{are} \mathrm{not} \mathrm{significantly}$ lower than those of the $3 \mathrm{kWp}$ case, as demonstrated in Figure 12.

More specifically, increasing the PV capacity more than three times (from $3 \mathrm{kWp}$ to $10 \mathrm{kWp}$ ) additionally reduced the emissions by only $25 \%$. To further explore this idea, the emissions reduction per installed PV capacity $\left(\mathrm{kgCO}_{2} / \mathrm{kWp}\right)$ were calculated for all of the previously explored PV cases. Figure 13 illustrates that the $10 \mathrm{kWp}$ generator achieves the lowest $\mathrm{CO}_{2}$ reduction per installed $\mathrm{kWp}$ (115.07-478.20 $\left.\mathrm{kgCO}_{2} / \mathrm{kWp}\right)$, compared to the $5 \mathrm{kWp}\left(204.19-832.96 \mathrm{kgCO}_{2} / \mathrm{kWp}\right)$ and the $3 \mathrm{kWp}$ generator (294.11-1117.16 $\mathrm{kgCO}_{2} / \mathrm{kWp}$ ) cases. One should note, however, that these values have been calculated considering the boundaries of each household individually. In reality, the excess PV generation that is exported to the grid will offset a portion of the electricity consumption of the neighboring consumers. As a result, larger PV capacities will increase the share of renewable energy in 
the power system and therefore reduce the $\mathrm{CO}_{2}$ emissions on a system level. In doing so, the rooftop PV generator of one's household contributes to the system-wide mitigation efforts, despite not achieving significant emissions reductions within its own boundaries. More specifically, PV exports, from a $10 \mathrm{kWp}$ generator, contribute to reducing the $\mathrm{CO}_{2}$ emissions of the Cypriot power sector by about $6828.87-11,278.16 \mathrm{kgCO}_{2}$ per year, or $9215.65 \mathrm{kgCO}_{2}$ on average.

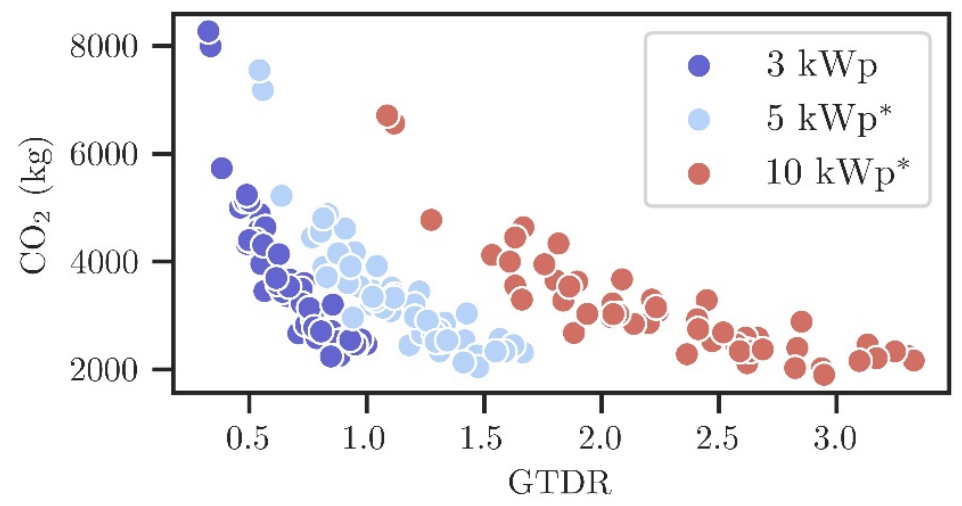

Figure 12. Annual household $\mathrm{CO}_{2}$ emissions as a function of GTDR $(\mathrm{n}=55)$. ( ${ }^{*}$ upscaled from $3 \mathrm{kWp}$ PV generation profiles).

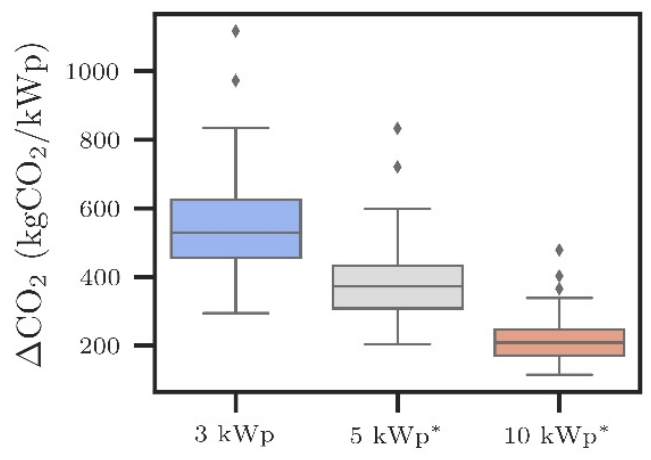

Figure 13. Reduction of $\mathrm{CO}_{2}$ emissions per installed PV capacity on a household level. (* upscaled from $3 \mathrm{kWp}$ PV generation profiles).

To take these dependencies into account, the analysis should be broadened outside the boundaries of a single building and towards a net zero energy community. An investigation of this topic may indeed be stimulating, but it is outside the scope of this paper and will not be discussed further.

The main takeaway from Figures 12 and 13 is that the $\mathrm{CO}_{2}$ emissions are very well correlated with the GTDR, regardless of the PV capacity. Based on this concept, simply increasing the PV capacity is not the best strategy in achieving this goal on a household level. In other words, the GTDR is a better indicator of the $\mathrm{CO} 2$ emissions reduction potential within the building boundaries than the PV capacity itself.

\section{Discussion}

The Cypriot power system is an islanded and dominantly fossil fuel-based system. This inherent inflexibility is rather unfortunate because Cyprus is among the countries with the highest solar potential in the EU. To utilize this fact, it has recently increased the PV capacity limit for net-metering installations to $10 \mathrm{kWp}$ and offers a subsidy program to all new prosumers ( $€ 5,000,000$ in total). Through this programme, owners of rooftop PV generators can receive a subsidy of up to $€ 1000$, while vulnerable owners (meeting specific socioeconomic criteria) can receive up to $€ 3600$ [41]. The declining PV installation cost in Cyprus is expected to significantly increase the penetration of residential PV systems under net-metering. As most of the rooftop PV experience in Cyprus comes from $3 \mathrm{kWp}$ PVs, it was 
necessary to explore the possible future impacts of the new legislation on the energy performance of households with larger PV capacities.

Initially, the results have demonstrated that the load matching capabilities of Cypriot households are governed by the cooling and heating demand. On an annual basis, a household with $3 \mathrm{kWp}$ PV generators has an average SCR of $48.17 \%$, which was found to be higher than what has been reported in the literature from similar analyses in the UK and Australia. With a PV capacity of $5 \mathrm{kWp}$, households had an average SCR of 34.05\%, reduced their annual remand by $2645 \mathrm{kWh}$ and exported about $5122.47 \mathrm{kWh}$ of the energy to the grid. If the analyzed households were to install a $10 \mathrm{kWp}$ PV generator, their load matching capabilities would decrease even further. As a result, the grid would have to accommodate additional exports of $10,119.80 \mathrm{kWh}$ and $7412.41 \mathrm{kWh}$, when compared to the $3 \mathrm{kWp}$, and $5 \mathrm{kWp}$ cases, respectively. Moreover, the results also showed that a $10 \mathrm{kWp}$ generator achieved lower $\mathrm{CO}_{2}$ reduction per installed $\mathrm{kWp}(115.07-478.20 \mathrm{kgCO} / \mathrm{kWp})$ when compared to the $5 \mathrm{kWp}(204.19-832.96 \mathrm{kgCO} 2 / \mathrm{kWp})$ and the $3 \mathrm{kWp}$ generator $(294.11-1117.16 \mathrm{kgCO} 2 / \mathrm{kWp})$. At the same time, however, it is worth noting that these exports are consumed elsewhere. Hence, they contribute to reducing the $\mathrm{CO}_{2}$ emissions on a system-wide level. In the specific case of the analyzed households, the PV exports are responsible for additionally reducing about $6828.87-11,278.16 \mathrm{kgCO}_{2}$. This clearly demonstrates that an oversized rooftop PV generator does not significantly outperform a properly sized one, with respect to the achieved self-sufficiency and emissions reduction within the building boundaries. However, as it results in notably larger exports, larger PV capacities contribute to higher system-wide emissions reductions. Hence, future issues from the additional stress on the old distribution grid in Cyprus could be anticipated if the installation of very large rooftop PVs goes unmanaged.

In a more general sense, the analysis provided some interesting observations with regards to the GTDR. While this value can be calculated or estimated quite easily, it provides a good indication of a household's energy performance, given it affects all of the analyzed parameters (SCR, SSR, LOLP and $\mathrm{CO}_{2}$ emissions). For example, one can expect a building that generates as much as it consumes $(G T D R=1.0)$ to have a higher self-consumption and lower exports that a household that generates twice the energy it consumes (GTDR $=2.0$ ), despite achieving comparable emissions reduction. Because of this, the GTDR can be used by stakeholders to infer possible value ranges of more complex indicators such as the SCR, SSR, LOLP and the $\mathrm{CO}_{2}$ emissions. As was demonstrated in this paper, this is possible if buildings are categorized with respect to GTDR. Once an extensive analysis has been performed over a wide population sample, policy makers can be informed of the concrete value ranges of SCR, SSR, LOLP and the $\mathrm{CO}_{2}$ reductions that should be expected for each GTDR category.

Within this framework, different policy measures can be proposed. These results are of significant importance to the activities of the PV-ESTIA project, especially with regards to the preparation of joint policy recommendations targeting grid operators and relevant stakeholders. For instance, households with a large GTDR (a limit can be introduced in the legislation) can be stimulated to undertake demand-side measures that will improve their self-consumption. Examples of such measures are the integration of a home energy management system that will schedule the operation of deferrable loads during daytime, or the installation of a battery energy storage system. Ten of the implemented pilots, within PV-ESTIA, consist of residential PV generators coupled with a battery storage unit. The project developed an innovative management scheme which reduces the impact of buildings with PVs on the grid and tested it in laboratory conditions. The findings of this paper can, therefore, be used to further adapt the innovative management scheme given the different building categories. This will enable households to utilize the larger PV capacity limits, but in a way that will have a low impact on the grid. Another approach would be to counter-incentivize households to oversize their rooftop PVs by changing the netting scheme. A self-consumption driven net-billing scheme is an example of such measure. When it is used, the price at which the exported PV generation is remunerated reduces as larger fractions of the PV generation are injected in the grid. 


\section{Conclusions and Outlook}

The statistical analysis of the energy consumption and PV generation of 55 Cypriot households led to the following conclusions: (1) best load-matching was achieved during the summer and winter months. Although this result was specific to Cyprus, it numerically demonstrates that load-matching is driven by a combination of consumption habits, climate conditions and local policy; (2) the analyzed load matching indicators (SCR, SSR and LOLP) are related to the GTDR; (3) oversized PVs only marginally reduce the on-site $\mathrm{CO}_{2}$ emissions within the building boundaries. At the same time, they reduce the system wide $\mathrm{CO}_{2}$ emissions, but at the cost of large amounts of exported energy; (4) the on-site $\mathrm{CO}_{2}$ emissions reduction of a household is related to its SSR.

With this in mind, policy maker need robust, but simple metrics that can guide their decision making for this complex issue. In that context, the GTDR has been identified as a practical indicator to be used for various policy measures related to rooftop PVs, as it provides a reliable estimate of other indicators such as SSR, SCR and LOLP. The GTDR can easily be integrated into legislation and used by policy makers to decide on possible measures in light of the dynamical developments of the rooftop PV legislation. Along with the findings of this work, a number of questions have risen from the analysis. In this paper, the GTDR ranges were arbitrarily chosen so as to populate each category as evenly as possible with the available data sample. Future research should try to determine these ranges so that they more accurately represent the different types of buildings. Moreover, the effects of energy storage should be explored with the aim of determining a threshold value of the GTDR above which stimulating self-consumption is most cost-beneficial.

Supplementary Materials: The following are available online at http://www.mdpi.com/1996-1073/13/8/1934/s1, Back of electricity bill containing data on grid factor for the analyzed year.

Author Contributions: Conceptualization, G.K.P., G.E.G. and G.C.C.; methodology, V.Z.G.; software, V.Z.G.; validation, N.G.C., G.C.C. and V.V.; formal analysis, V.Z.G.; investigation, V.Z.G. and N.G.C.; resources, G.E. G.V.V., N.G.C.; data curation, V.V. and V.Z.G.; writing-original draft preparation, V.Z.G.; writing-review and editing, N.G.C. and G.C.C.; visualization, V.Z.G.; supervision, G.C.C.; project administration, G.K.P.; funding acquisition, G.K.P. and G.C.C. All authors have read and agreed to the published version of the manuscript.

Funding: This research and the APC were funded by the project "Enhancing Storage Integration in Buildings with Photovoltaics-PV-ESTIA" which is co-financed by the Interreg Balkan-Mediterranean programme of the European Union under the subsidy contr act number BMP1/22/2338/2017.

Acknowledgments: The prosumers' data used in this paper come from the FOSS Research Centre for Sustainable Energy of the University of Cyprus and the SmartPV project, co-financed by the programme LIFE of the European Union under the grant agreement number LIFE 12/ENV/CY/000276 and their contribution is highly acknowledged.

Conflicts of Interest: The authors declare no conflict of interest. The funders had no role in the design of the study; in the collection, analyses, or interpretation of data; in the writing of the manuscript, or in the decision to publish the results.

\section{References}

1. IEA. Tracking Buildings; IEA: Paris, France, 2019.

2. IEA. World Energy Statistics and Balances; IEA: Paris, France, 2019.

3. Wang, H.; Chen, W.; Shi, J. Low carbon transition of global building sector under 2- and 1.5-degree targets. Appl. Energy 2018, 222, 148-157. [CrossRef]

4. Mancini, F.; Nastasi, B. Energy retrofitting effects on the energy flexibility of dwellings. Energies 2019, 12, 2788. [CrossRef]

5. Bódis, K.; Kougias, I.; Jäger-Waldau, A.; Taylor, N.; Szabó, S. A high-resolution geospatial assessment of the rooftop solar photovoltaic potential in the European Union. Renew. Sustain. Energy Rev. 2019, 114, 109309. [CrossRef]

6. Gupta, R.; Gregg, M. Do deep low carbon domestic retrofits actually work? Energy Build. 2016, 129, 330-343. [CrossRef] 
7. European Parliament Directive (EU) 2018/844 of the European Parliament and of the Council of 30 May 2018 amending Directive 2010/31/EU on the energy performance of buildings and Directive 2012/27/EU on energy efficiency. Off. J. Eur. Union 2018, 128, 83-206.

8. D'Agostino, D. Assessment of the progress towards the establishment of definitions of Nearly Zero Energy Buildings (nZEBs) in European Member States. J. Build. Eng. 2015, 1, 20-32. [CrossRef]

9. Kurnitski, J.; Allard, F.; Braham, D.; Goeders, G.; Heiselberg, P.; Jagemar, L.; Kosonen, R.; Lebrun, J.; Mazzarella, L.; Railio, J.; et al. How to define nearly net zero energy buildings nZEB. REHVA J. 2012, 48, 6-12.

10. Verbruggen, B.; Driesen, J. Grid impact indicators for active building simulations. IEEE Trans. Sustain. Energy 2014, 6, 43-50. [CrossRef]

11. Finance, B.N.E. New Energy Outlook. 2019. Available online: https://about.bnef.com/new-energy-outlook (accessed on 6 April 2020).

12. Nousdilis, A.I.; Christoforidis, G.C.; Papagiannis, G.K. Active power management in low voltage networks with high photovoltaics penetration based on prosumers' self-consumption. Appl. Energy 2018, 229, 614-624. [CrossRef]

13. PV-ESTIA Project. Available online: https://www.pv-estia.eu/ (accessed on 24 February 2020).

14. Salom, J.; Widén, J.; Candanedo, J.; Sartori, I.; Voss, K.; Marszal, A. Understanding net zero energy buildings: Evaluation of load matching and grid interaction indicators. In Proceedings of the proceedings of building simulation, Sydney, Australia, 14-16 November 2011; pp. 2514-2521.

15. McKenna, E.; Webborn, E.; Leicester, P.; Elam, S. Analysis of international residential solar PV self-consumption. In Proceedings of the ECEEE 2019 Summer Study proceedings, Presqu'île de Giens, France, 3-8 June 2019.

16. Luthander, R.; Widén, J.; Munkhammar, J.; Lingfors, D. Self-consumption enhancement and peak shaving of residential photovoltaics using storage and curtailment. Energy 2016, 112, 221-231. [CrossRef]

17. Salpakari, J.; Lund, P. Optimal and rule-based control strategies for energy flexibility in buildings with PV. Appl. Energy 2016, 161, 425-436. [CrossRef]

18. Williams, C.J.; Binder, J.O.; Kelm, T. Demand side management through heat pumps, thermal storage and battery storage to increase local self-consumption and grid compatibility of PV systems. In Proceedings of the 2012 3rd IEEE PES Innovative Smart Grid Technologies Europe (ISGT Europe), Berlin, Germany, 14-17 October 2012; pp. 1-6.

19. Luthander, R.; Widén, J.; Nilsson, D.; Palm, J. Photovoltaic self-consumption in buildings: A review. Appl. Energy 2015, 142, 80-94. [CrossRef]

20. Gautier, A.; Hoet, B.; Jacqmin, J.; Driessche, S. Van Self-consumption choice of residential PV owners under net-metering. Energy Policy 2019, 128, 648-653. [CrossRef]

21. Bertsch, V.; Geldermann, J.; Lühn, T. What drives the profitability of household PV investments, self-consumption and self-sufficiency? Appl. Energy 2017, 204, 1-15. [CrossRef]

22. Mubarak, R.; Luiz, E.W.; Seckmeyer, G. Why PV modules should preferably no longer be oriented to the south in the near future. Energies 2019, 12, 4528. [CrossRef]

23. Yu, H.; Julie, J. A prospective economic assessment of residential PV self-consumption with batteries and its systemic effects: The French case in 2030. Energy Policy 2018, 113, 673-687. [CrossRef]

24. European Commission. Best Practices on Renewable Energy Self-Consumption; European Commission: Brussels, Belgium, 2015.

25. DECC. Impact Assessment: Government Response to Consultation on a Review of the Feed-in Tariff Scheme. Available online: https://www.gov.uk/government/consultations/consultation-on-a-review-of-the-feed-intariff-scheme (accessed on 6 April 2020).

26. McKenna, E.; Pless, J.; Darby, S.J. Solar photovoltaic self-consumption in the UK residential sector: New estimates from a smart grid demonstration project. Energy Policy 2018, 118, 482-491. [CrossRef]

27. Roberts, M.B.; Haghdadi, N.; Bruce, A.; MacGill, I. Characterisation of Australian apartment electricity demand and its implications for low-carbon cities. Energy 2019, 180, 242-257. [CrossRef]

28. Speirs, J.; Contestabile, M.; Houari, Y.; Gross, R. The future of lithium availability for electric vehicle batteries. Renew. Sustain. Energy Rev. 2014, 35, 183-193. [CrossRef]

29. Christoforidis, G.C.; Panapakidis, I.P.; Papadopoulos, T.A.; Papagiannis, G.K.; Koumparou, I.; Hadjipanayi, M.; Georghiou, G.E. A model for the assessment of different Net-Metering policies. Energies 2016, 9, 262. [CrossRef] 
30. Luthander, R.; Nilsson, A.M.; Widén, J.; Åberg, M. Graphical analysis of photovoltaic generation and load matching in buildings: A novel way of studying self-consumption and self-sufficiency. Appl. Energy 2019, 250, 748-759. [CrossRef]

31. Smart PV Project. Available online: http://www.smartpvproject.eu/ (accessed on 24 February 2020).

32. Venizelou, V.; Makrides, G.; Efthymiou, V.; Georghiou, G.E. Methodology for deploying cost-optimum price-based demand side management for residential prosumers. Renew. Energy 2020, 153, 228-240. [CrossRef]

33. Statistical Service. Final Energy Consumption in Households; Statistical Service: Nicosia, Cyprus, 2009.

34. Electricity Authority of Cyprus Net-Metering Scheme. Available online: https://www.eac.com.cy/EN/ RegulatedActivities/Supply/renewableenergy/Pages/netmetering.aspx (accessed on 3 March 2020).

35. Venizelou, V.; Philippou, N.; Hadjipanayi, M.; Makrides, G.; Efthymiou, V.; Georghiou, G.E. Development of a novel time-of-use tariff algorithm for residential prosumer price-based demand side management. Energy 2018, 142, 633-646. [CrossRef]

36. Republic of Cyprus, Solar Energy for Al 1- Plan for the promotion of Photovoltaic systems. Available online:

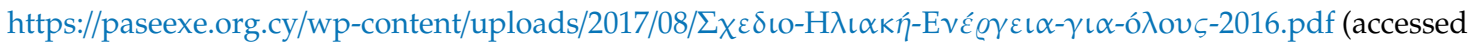
on 6 April 2020).

37. Republic of Cyprus. Renewable Energy for All-Plan for electricity production from Renewable Energy Sources for Own Use. Available online: http://www.cea.org.cy/wp-content/uploads/2018/07/schedio-giaparagogi-ilektrikis-energeias-gia-idia-katanalosi-net-metering-net-billing.pdf (accessed on 6 April 2020).

38. Cyprus Energy Regulatory Authority. Annual report 2018. Available online: https://www.cera.org.cy/ Templates/00001/data/ektheseis/2018_gr.pdf (accessed on 6 April 2020).

39. Fares, R.L.; Webber, M.E. The impacts of storing solar energy in the home to reduce reliance on the utility. Nat. Energy 2017, 2, 17001. [CrossRef]

40. Gjorgievski, V.; Cundeva, S. The effects of residential battery storage on grid impact indicators. In Proceedings of the 2019 IEEE Milan PowerTech (PowerTech 2019), Milan, Italy, 23-27 June 2019.

41. Ministry of Energy Commerce and Industry of Cyprus Subsidy Program for Rooftop PV. Available online: http: //www.mcit.gov.cy/mcit/EnergySe.nsf/All/17C64F75EAEBF341C22583B7003E00F6?OpenDocument (accessed on 24 February 2020).

(C) 2020 by the authors. Licensee MDPI, Basel, Switzerland. This article is an open access article distributed under the terms and conditions of the Creative Commons Attribution (CC BY) license (http://creativecommons.org/licenses/by/4.0/). 